\title{
The Evolution of the Concept of Fuzzy Measure.
}

\author{
Luis Garmendia \\ Facultad de Informática, Dep. Sistemas Informáticos y Programación, \\ Universidad Complutense of. Madrid, Spain, E-mail: \\ lgarmend@fdi.ucm.es, Web Page: www.fdi.ucm.es/profesor/lgarmend
}

\begin{abstract}
Most information discovery processes need to understand the reasons of the success of the inference methods or the usability of the new information, which can sometimes be somehow explained with a few useful measures on the premises or on the chosen relations, logics and implications. This chapter presents a state of art on the latest concepts of measure, from the additive measures, to monotone fuzzy measures and the latest monotone measures in relation to a preorder that gives an ordering for a measurable characteristic. A few measures on fuzzy sets and fuzzy relations are proposed. Namely, the entropy measures on fuzzy sets, which are a measure of fuzziness in itself, and the specificity measures on fuzzy sets, which cam be understood as measures of utility of the information contained in a fuzzy set. Some measures on fuzzy relations to be considered are the conditionality measures, which are degrees of generalization of modus ponens when making fuzzy inference. Those measures on fuzzy sets and fuzzy relations provide interesting information on fuzzy inference and approximate reasoning processes.
\end{abstract}

Keywords: fuzzy measure, approximate reasoning, conditionality, specificity.

\section{Introduction}

The discovery of useful information is the essence of any data mining process. Decisions are not usually taken based on complete real world data, but most of the times they deal with uncertainty or lack of informa- 
tion. Therefore the real world reasoning is almost always approximate. However it is not only necessary to learn new information in any data mining process, but it is also important to understand why and how the information is discovered. Most data mining commercial products are black boxes that do not explain the reasons and methods that have been used to get new information. However the 'why and how' the information is obtained can be as important as the information on its own. When approximate reasoning is done, measures on fuzzy sets and fuzzy relations can be proposed to provide a lot of information that helps to understand the conclusions of fuzzy inference processes. Those measures can even help to make decisions that allow to use the most proper methods, logics, operators for connectives and implications, in every approximate reasoning environment.

The latest concepts of measures in approximate reasoning is discussed and a few measures on fuzzy sets and fuzzy relations are proposed to be used to understand why the reasoning is working and to make decisions about labels, connectives or implications, and so a few useful measures can help to have the best performance in approximate reasoning and decision making processes.

Before some measures on fuzzy sets and fuzzy relations are proposed, this chapter collects all the latest new concepts and definitions on measures, and shows a few graphics that make a clear picture on how those measures can be classified.

Some important measures on fuzzy sets are the entropy measures and specificity measures. The entropy measures give a degree of fuzziness of a fuzzy set, which can be computed by the premises or outputs of an inference to know an amount of uncertainty crispness in the process. Specificity measures of fuzzy sets give a degree of the utility of information contained in a fuzzy set.

Other important measures can be computed on fuzzy relations. For example, some methods to measure a degree of generalisation of the MODUS PONENS property in fuzzy inference processes are proposed.

\section{The Concept of Measure}

The concept of measure is one of the most important concepts in mathematics, as well as the concept of integral respect to a given measure. The classical measures are supposed to hold the additive property. Additivity can be very effective and convenient in some applications, but can also be somewhat inadequate in many reasoning environments of the real world as 
in approximate reasoning, fuzzy logic, artificial intelligence, game theory, decision making, psychology, economy, data mining, etc., that require the definition of non additive measures and a large amount of open problems. For example, the efficiency of a set of workers is being measured, the efficiency of the same people doing teamwork is not the addition of the efficiency of each individual working on their own.

The concept of fuzzy measure does not require additivity, but it requires monotonicity related to the inclusion of sets. The concept of fuzzy measure can also be generalised by new concepts of measure that pretend to measure a characteristic not really related with the inclusion of sets. However those new measures can show that "x has a higher degree of a particular quality than y" when $\mathrm{x}$ and $\mathrm{y}$ are ordered by a preorder (not necessarily the set inclusion preorder).

The term fuzzy integral uses the concept of fuzzy measure. There are some important fuzzy integrals, as Choquet integral in 1974, which does not require an additive measure (as Lebesgue integral does). Michio Sugeno gives other new integral in 1974 for fuzzy sets, and so does David Schmeidler in 1982 for decision theory.

\subsection{Preliminaries}

A measurable space is a couple $(X, \wp)$ where $X$ is a set and $\wp$ is a $\sigma$ algebra or set of subsets of $\mathrm{X}$ such that:

1. $X \in \wp$.

2. Let $A$ be a subset of $X$. If $A \in \wp$ then $A^{\prime} \in \wp$.

3. If $A_{n} \in \wp$ then $\bigcup_{n=1}^{\infty} A_{n} \in \wp$.

For example, when $\mathrm{X}$ is the set of real numbers and $\wp$ is the $\sigma$-algebra that contains the open subsets of $X$, then $\wp$ is the well-known Borel $\sigma$-algebra.

\section{Note:}

The classical concept of measure considers that $\wp \subseteq\{0,1\}^{\mathrm{X}}$, but this consideration can be extended to a set of fuzzy subsets $\mathfrak{I}$ of $X, \mathfrak{I} \subseteq[0,1]^{\mathrm{X}}$, satisfying the properties of measurable space $\left([0,1]^{\mathrm{X}}, \mathfrak{I}\right)$. 


\subsection{Definition of Additive Measure:}

Let $(X, \wp)$ be a measurable space. A function m: $\wp \rightarrow[0, \propto)$ is an $\sigma-$ additive measure when the following properties are satisfied:

1. $\mathrm{m}(\varnothing)=0$.

2. If $A_{n}, n=1,2, \ldots$ is a set of disjoint subsets of $\wp$ then

3. $m\left(\bigcup_{n=1}^{\infty} A_{n}\right)=\sum_{n=1}^{\infty} m\left(A_{n}\right)$

The second property is called $\sigma$-additivity, and the additive property of a measurable space requires the $\sigma$-additivity in a finite set of subsets $A_{n}$.

A well-known example of $\sigma$-additive is the probabilistic space $(X, \wp, p)$ where the probability $\mathrm{p}$ is an additive measure such that $\mathrm{p}(\mathrm{X})=1$ and $\mathrm{p}(\mathrm{A})=1-\mathrm{p}\left(\mathrm{A}^{\prime}\right)$ for all subsets $\mathrm{A} \in \wp$.

Other known examples of $\sigma$-additive measure are the Lebesgue measures defined in 1900 that are an important base of the XX century mathematics. The Lebesgue measures generalise the concept of length of a segment, and verify that if $[c, d] \subset \bigcup_{i=1}^{n}\left[a_{i}, b_{i}\right)$ then $d-c \leq \sum_{i=1}^{n}\left(b_{i}-a_{i}\right)$. Other measures given by Lebesgue are the exterior Lebesgue measures and interior Lebesgue measures. A set A is Lebesgue measurable when both interior and exterior Lebesgue measures are the same. Some examples of Lebesgue measurable sets are the compact sets, the empty set and the real numbers set $\mathfrak{R}$.

\subsection{Definition of Normal Measure}

Let $(X, \wp)$ be a measurable space. A measure $m: \wp \rightarrow[0,1]$ is a normal measure if there exists a minimal set $\mathrm{A}_{0}$ and a maximal set $\mathrm{A}_{\mathrm{m}}$ in $\wp$ such that:

1. $\mathrm{m}\left(\mathrm{A}_{0}\right)=0$.

2. $m\left(A_{m}\right)=1$.

For example, the measures of probability on a space $(X, \wp)$ are normal measures with $A_{0}=\varnothing$ and $A_{m}=X$. The Lebesgue measures are not necessarily normal. 
2.4 Definition of Sugeno Fuzzy Measure [Murofushi and Sugeno; 1989]

Let $\wp$ be an $\sigma$-algebra on a universe X. A Sugeno fuzzy measure is g: $\wp \rightarrow[0,1]$ verifying:

1. $g(\varnothing)=0, g(X)=1$.

2. If $\mathrm{A}, \mathrm{B} \in \wp$ and $\mathrm{A} \subseteq \mathrm{B}$ then $\mathrm{g}(\mathrm{A}) \leq \mathrm{g}(\mathrm{B})$.

3. If $A_{n} \in \wp$ and $A_{1} \subseteq A_{2} \subseteq \ldots$ then $\lim _{n \rightarrow \infty} g\left(A_{n}\right)=g\left(\lim _{n \rightarrow \infty} A_{n}\right)$

Property 2 is called monotony and property 3 is called Sugeno's convergence.

The Sugeno measures are monotone but its main characteristic is that additivity is not needed.

Banon [1981] shows that several measures on finite algebras, as probability, credibility measures and plausibility measures are Sugeno measures. The possibility measures on possibility distributions introduced by Zadeh [1978] gives Sugeno measures.

\subsection{Theory of Evidence}

The theory of evidence is based on two dual non-additive measures: belief measures and plausibility measures.

Given a measurable space $(X, \wp)$, a belief measure is a function Bel: $\wp \rightarrow[0,1]$ verifying the following properties:

1 . $\operatorname{Bel}(\varnothing)=0$.

2. $\operatorname{Bel}(X)=1$.

3. $\operatorname{Bel}(A \cup B) \geq \operatorname{Bel}(A)+\operatorname{Bel}(B)$.

Property 3 is called superadditivity. When $X$ is infinite, the superior continuity of the function Bel is required. For every $\mathrm{A} \in \wp, \mathrm{Bel}(\mathrm{A})$ is interpreted as a belief degree for some element to be in the set A.

From the definition of belief measure, it can be proved that $\operatorname{Bel}(\mathrm{A})+$ $\operatorname{Bel}\left(\mathrm{A}^{\prime}\right) \leq 1$.

Given a belief measure, its dual plausibility measure can be defined as $\operatorname{Pl}(\mathrm{A})=1-\operatorname{Cred}\left(\mathrm{A}^{\prime}\right)$.

Given a measurable space $(\mathrm{X}, \wp)$ a measure of plausibility is a function $\mathrm{Pl}: \wp \rightarrow[0,1]$ such that

1. $\operatorname{Pl}(\varnothing)=0$.

2. $\mathrm{Pl}(\mathrm{X})=1$.

3. $\mathrm{Pl}(\mathrm{A} \cup \mathrm{B}) \leq \mathrm{Pl}(\mathrm{A})+\mathrm{Pl}(\mathrm{B})$.

Property 3 is called subadditivity.

When $\mathrm{X}$ is infinite, the inferior continuity of the function $\mathrm{Pl}$ is required. 
It can be proved that $\mathrm{Pl}(\mathrm{A})+\mathrm{Pl}\left(\mathrm{A}^{\prime}\right) \geq 1$.

The measures of credibility and plausibility are defined by a function $\mathrm{m}$ : $\wp \rightarrow[0,1]$ such that $\mathrm{m}(\varnothing)=0$ and $\sum_{\mathrm{A} \in \wp} \mathrm{m}(\mathrm{A})=1$ where $\mathrm{m}$ represents a proportion of the shown evidence that an element of $\mathrm{X}$ is in a subset $\mathrm{A}$.

\subsection{Theory of Possibility}

The theory of possibility is a branch of theory of evidence where the plausibility measures verify that $\mathrm{Pl}(\mathrm{A} \cup \mathrm{B})=\max \{\mathrm{Pl}(\mathrm{A}), \mathrm{Pl}(\mathrm{B})\}$. Such plausibility measures are called possibility measures. In the theory of possibility, the belief measures satisfy that $\operatorname{Bel}(A \cap B)=\min \{\operatorname{Bel}(A), B e l(B)\}$ and are called necessity measures.

Definition 1 [Zadeh; 1978, Higashi \& Klir; 1983]

Let $(X, \wp)$ be a measurable space. A possibility measure is a function $\Pi$ : $\wp \rightarrow[0,1]$ that verifies the following properties:

1. $\Pi(\varnothing)=0, \Pi(X)=1$.

2. $\mathrm{A} \subseteq \mathrm{B} \Rightarrow \Pi(\mathrm{A}) \leq \Pi(\mathrm{B})$

3. $\Pi\left(\bigcup_{i \in I} A_{i}\right)=\sup _{i \in I}\left\{\Pi\left(A_{i}\right)\right\}$ for a set of indexes I.

The possibility measures are sub additive normal measures.

Definition 2 [Zadeh; 1978, Higashi \& Klir; 1983]

Let $(X, \wp)$ be a measurable space. A necessity measure is a function Nec: $\wp \rightarrow[0,1]]$ that verifies the following properties:

1. $\operatorname{Nec}(\varnothing)=0, \operatorname{Nec}(X)=1$.

2. $\mathrm{A} \subseteq \mathrm{B} \Rightarrow \operatorname{Nec}(\mathrm{A}) \leq \mathrm{Nec}(\mathrm{B})$

3. $\operatorname{Nec}\left(\bigcap_{i \in I} A_{i}\right)=\inf _{i \in I}\left\{\operatorname{Nec}\left(A_{i}\right)\right\}$ for any set I.

Possibility measures are plausibility measures and necessity measures are belief measures, so:

1. $\Pi(\mathrm{A})+\Pi\left(\mathrm{A}^{\prime}\right) \geq 1$.

2. $\operatorname{Nec}(A)+\operatorname{Nec}\left(A^{\prime}\right) \leq 1$.

3. $\operatorname{Nec}\left(A^{\prime}\right)=1-\Pi\left(A^{\prime}\right)$.

4. $\max \left\{\Pi(\mathrm{A}), \Pi\left(\mathrm{A}^{\prime}\right)\right\}=1$.

5. $\min \left\{\operatorname{Nec}\left(\mathrm{A}^{\prime}\right), \operatorname{Nec}\left(\mathrm{A}^{\prime}\right)\right\}=0$.

6. $\operatorname{Nec}(A)>0 \Rightarrow \Pi(A)=1$.

7. $\Pi(A)<1 \Rightarrow \operatorname{Nec}(A)=0$. 
The Shafer [1976] theory of evidence stands that the probability of an element or a set is related to its complementary one. It includes concepts of 'low probability' and 'high probability', that are related to the measures of possibility and necessity in the sense that for any subset A, Nec(A) $\leq \mathrm{P}(\mathrm{A})$ $\leq \Pi(\mathrm{A})$.

The theory of possibility also stands on fuzzy sets, where $\wp$ is a family of fuzzy subsets in X.

A measure of possibility is not always a Sugeno fuzzy measure [Puri \& Ralescu 1982]. However a normal possibility distribution on a finite universe $\mathrm{X}$ is a Sugeno measure.

2.7 Definition of Fuzzy Measure [Nguyen \& Walker, 1996, 183]

Let $(\mathrm{X}, \wp)$ be a measurable space. A function m: $\wp \rightarrow[0, \propto)$ is a fuzzy measure (or monotone measure) if it verifies the following properties:

1. $\mathrm{m}(\varnothing)=0$.

2. If $A, B \in \wp$ and $A \subseteq B$ then $m(A) \leq m(B)$.

Property 2 is called monotony.

For example, all $\sigma$-additive measures (as probability) are fuzzy measures. Some other fuzzy measures are the necessity measures, the possibility measures and the Sugeno measures.

The figure 1 represents a typology of the most important monotone and normal measures. 


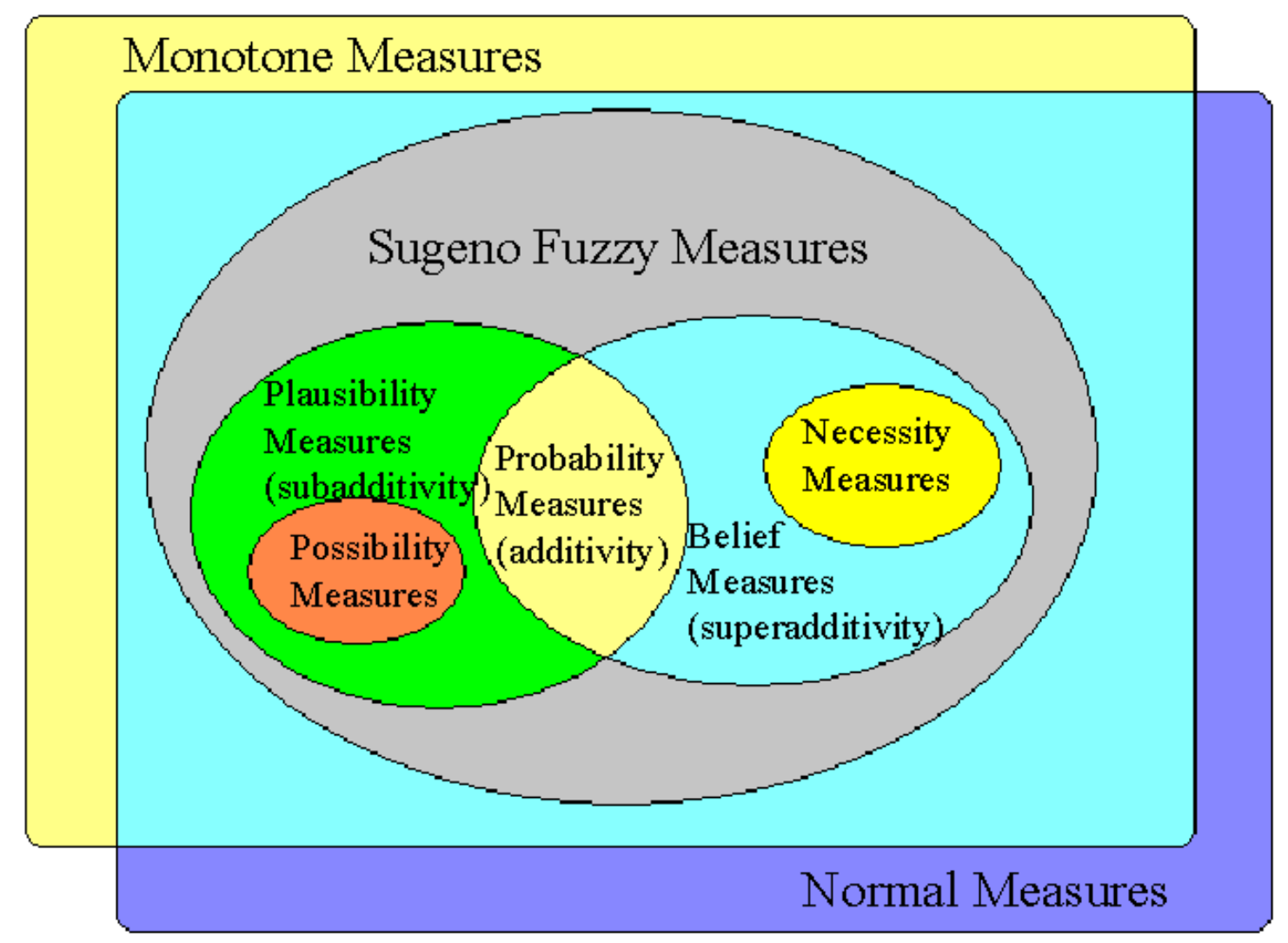

Figure 1: Monotone and normal measures

\subsection{Definition of Fuzzy Sugeno $\lambda$-Measure}

Sugeno [1974] introduces the concept of fuzzy $\lambda$-measure as a normal measure that is $\lambda$-additive. So the fuzzy $\lambda$-measures are fuzzy (monotone) measures.

Let $\lambda \in(-1, \propto)$ and let $(\mathrm{X}, \wp)$ be a measurable space. A function $\mathrm{g}_{\lambda}: \wp \rightarrow$ $[0,1]$ is a fuzzy $\lambda$-measure if for all disjoint subsets $A, B$ in $\wp, g_{\lambda}(A \cup B)$ $=\mathrm{g}_{\lambda}(\mathrm{A})+\mathrm{g}_{\lambda}(\mathrm{B})+\lambda \mathrm{g}_{\lambda}(\mathrm{A}) \mathrm{g}_{\lambda}(\mathrm{B})$.

For example, if $\lambda=0$ then the fuzzy $\lambda$-measure is an additive measure. 


\subsection{S-Decomposable Measures}

Weber [1984] defined the S-decomposable measures providing a general concept of the fuzzy $\lambda$-measures and the possibility measures.

Let $\mathrm{S}$ be a t-conorm, and let $(\mathrm{X}, \wp)$ be a measurable space. A Sdecomposable measure is a function $\mathrm{m}: \wp \rightarrow[0,1]$ that verifies the following conditions.

1. $\mathrm{m}(\varnothing)=0$.

2. $\mathrm{m}(\mathrm{X})=1$.

3. For all disjoint subsets $A$ and $B$ in $\wp, m(A \cup B)=S(m(A), m(B))$.

The property 3 is called $\boldsymbol{S}$-additivity.

For example, the probability measures are $\mathrm{W}^{*}$-decomposable measures, where $\mathrm{W}^{*}$ is the Lukasiewicz t-conorm. The $\mathrm{W}^{*}{ }_{\lambda}$-decomposable measures, where $\mathrm{W}_{\lambda}^{*}$ is the $\mathrm{t}$-conorm $\mathrm{W}_{\lambda}(\mathrm{x}, \mathrm{y})=\mathrm{x}+\mathrm{y}+\lambda \mathrm{xy}$ are fuzzy $\lambda$-measures.

Let $\mathrm{m}$ be a $\mathrm{S}$-decomposable measure on $(\mathrm{X}, \wp)$. If $\mathrm{X}$ is finite then given a subset $\mathrm{A}$ in $\wp, \mathrm{m}(\mathrm{A})=\underset{\mathrm{x} \in \mathrm{A}}{\mathrm{S}}\{\mathrm{m}(\{\mathrm{x}\})\}$.

The figure 2 shows the relation between Sugeno fuzzy measures and Sdecomposable measures.

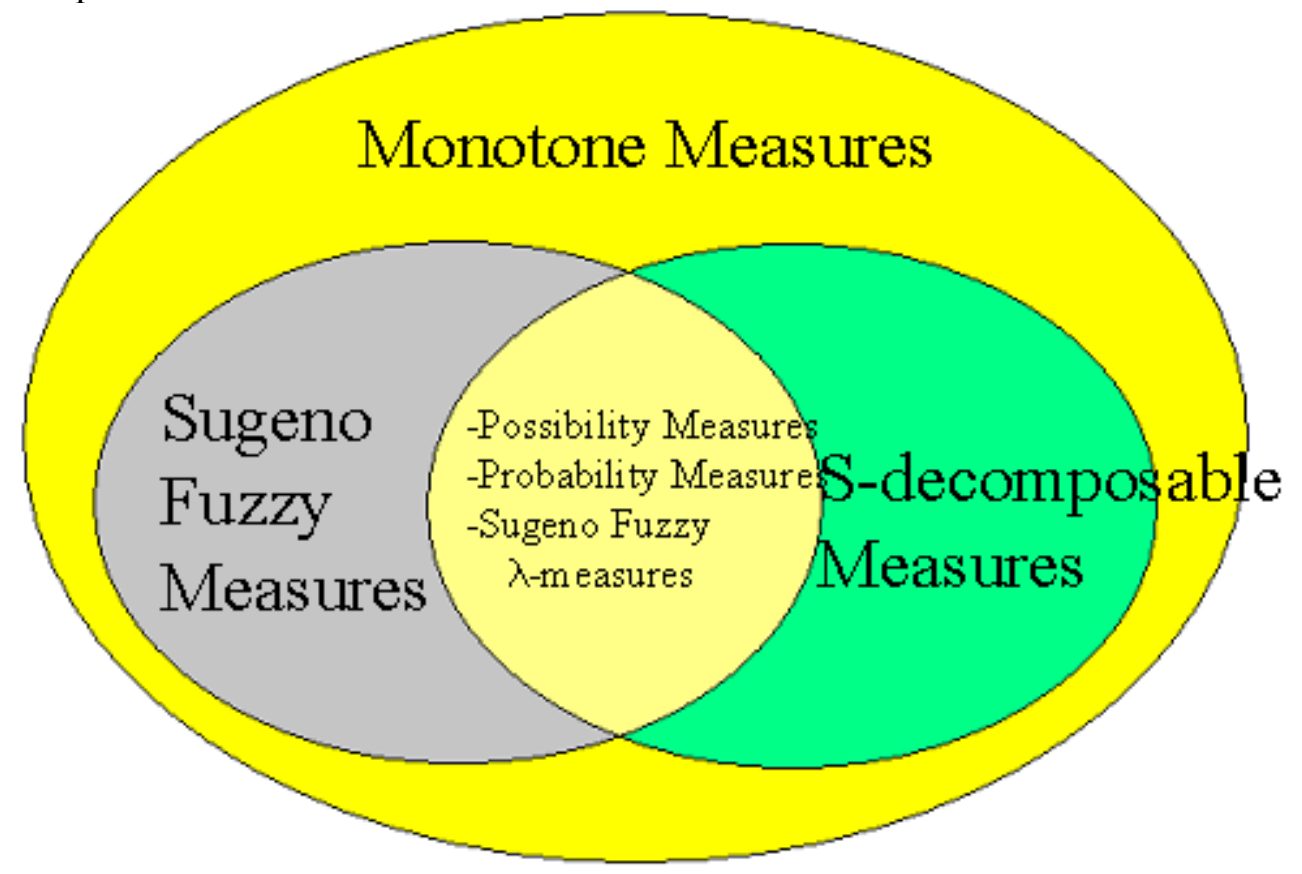

Figure 2: Relation between S-decomposable measures and Sugeno measures 


\subsection{Fuzzy $\prec$-Measure ( Fuzzy Preorder-Monotone Measure)}

Trillas and Alsina [Trillas \& Alsina; 1999] give a general definition of fuzzy measure. When a characteristic, namely -volume, weight, etc.- needs to be measured on the elements of a set $\mathrm{X}$, a preorder relation that allows to stand that " $x$ shows the characteristic less than $\mathrm{y}$ shows it" for all $\mathrm{x}$ and $\mathrm{y}$ in $\mathrm{X}$ is necessary to be set. That reflexive and transitive relation is denoted $x \prec y$.

A fuzzy $\prec$-measure is defined as follows:

Let $\prec$ be a preorder, for which 0 is a minimal element in $\mathrm{X}$ and $\mathbf{1}$ is a maximal element in $\mathrm{X}$. Then a fuzzy $\prec$-measure is a function $\mathrm{m}: \wp(\mathrm{X}) \rightarrow$ $[0,1]$ that verifies the following conditions:

1. $\mathrm{m}(0)=0$

2. $\mathrm{m}(1)=1$

3. If $x \prec y$ then $\mathrm{m}(x) \leq \mathrm{m}(y)$.

A good example of fuzzy $\prec$-measure on the set of natural numbers $\mathrm{N}$ is the Sarkovskii measure, which is defined as a measure of approximately even numbers, given by the following function $\mathrm{m}$ :

$$
m(n)=\left\{\begin{array}{cc}
1 & \text { if } \mathrm{n}=2^{\mathrm{k}} \text { for } \mathrm{k}=0,1,2, \ldots \\
0 & \text { if } \mathrm{n}=2^{\mathrm{k}}+1 \text { for } \mathrm{k}=1,2, \ldots \\
1-\frac{1}{2^{k}} & \text { if } \mathrm{n}=2^{\mathrm{k}}(2 p+1) \text { for } \mathrm{k}=1,2, \ldots \mathrm{p}=1,2, \ldots
\end{array}\right.
$$

Then $m$ is a fuzzy $\prec$-measures, not for the normal natural numbers order, but for the Sarkovskii order, for which the lowest number is 3, and the greatest number is 1 . It is a well-known order used in dynamic systems and given defined as follows:

$$
\begin{aligned}
3 & \prec 5 \prec 7 \prec \ldots \prec 2.3 \prec 2.5 \prec \ldots \prec 2^{2} .3 \prec 2^{2} .5 \prec \ldots \prec 2^{3} .3 \prec 2^{3} .5 \prec \ldots 2^{3} .3 \\
\prec 2^{3} & \prec 2^{2} \prec 2 \prec 1
\end{aligned}
$$

Other fuzzy $\prec$-measure are all previous defined fuzzy measures, which are monotone measures with respect to the set inclusion preorder, that is now generalised in both classic set inclusion and fuzzy set inclusion cases. The Sugeno [Sugeno; 1974] fuzzy measure concept is also generalised: if $\wp$ is a partial order lattice, then $x \prec y$ if and only if $x \wedge y=x$, and the three Sugeno properties are satisfied. If the lattice is ortocomplemented then there exists a dual function $\mathrm{m}^{*}(x)=1-\mathrm{m}\left(x^{\prime}\right)$ that at the same time is a fuzzy $\prec$-measure.

Then, the probability measure on a Boole algebra of probabilistic successes is also a fuzzy $\prec$-measure. 
Let $\wp$ be the set of fuzzy subsets on a given set, the entropy measure introduced by De Luca and Termini [1972], and the possibility or necessity measures [Higashi \& Klir; 1983] are also a fuzzy $\prec$-measures.

The figure 3 shows graphically the relation between different measures and a classification of many of the given examples

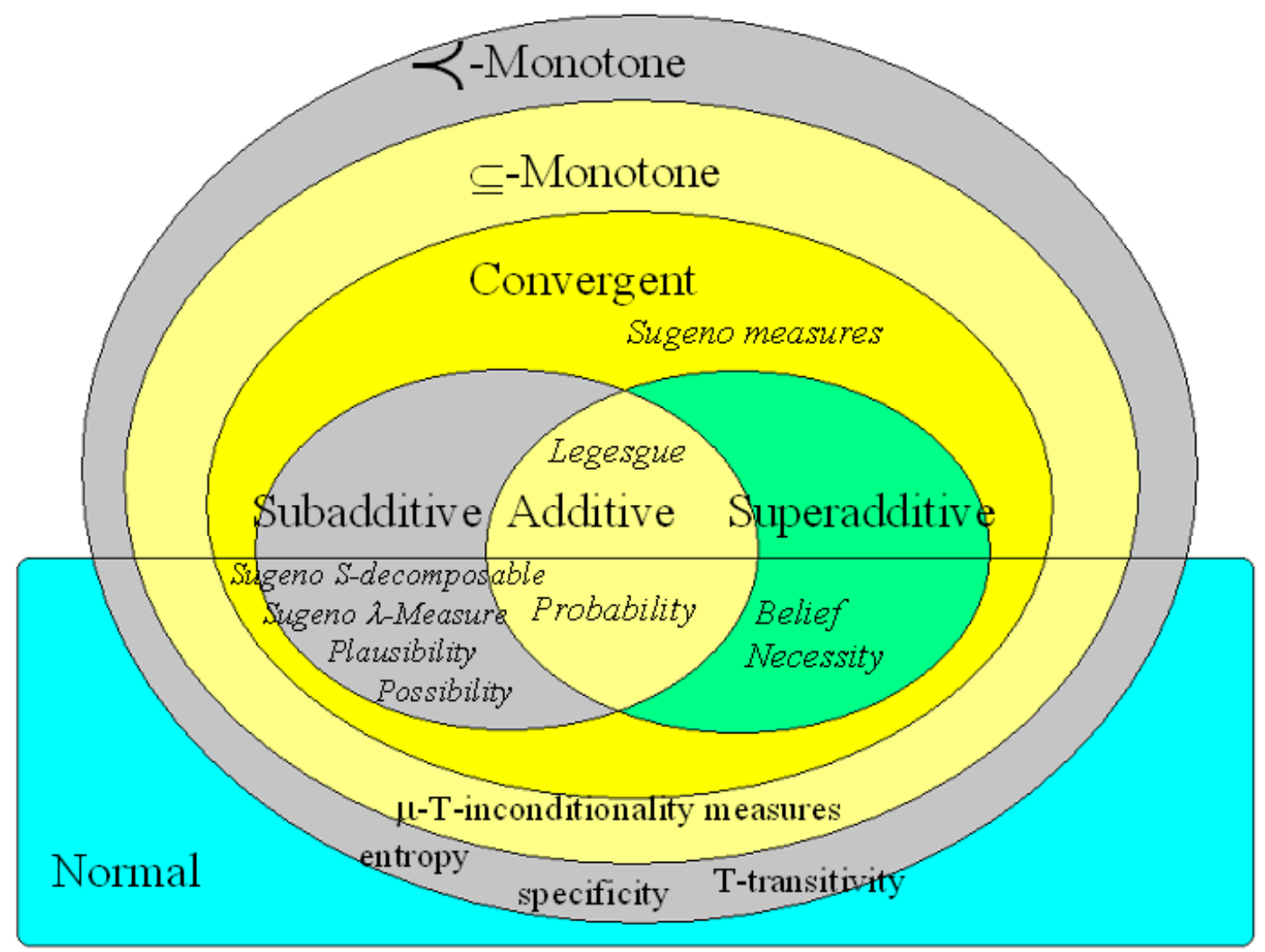

Figure 3: relation between different measures and a classification of some examples 


\section{Some Measures On Fuzzy Sets and Fuzzy Relations}

\subsection{Entropy or Measures of Fuzziness}

Let $X$ be a set and let $\wp(X)$ be the set of fuzzy sets on $X$. The measures of fuzziness or entropies give a degree of fuzziness for every fuzzy set in $\wp$. Some entropy measures have influence from the Shannon probabilistic entropy, which is commonly used as measures of information.

De Luca and Termini [1972] consider the entropy E of a fuzzy set of $\wp(\mathrm{X})$ as a measure that gives a value in $[0, \propto]$ and satisfies the following properties:

1. $\mathrm{E}(\mathrm{A})=0$ if $\mathrm{A}$ is a crisp set.

2. $E(A)$ is maximal if $A$ is the constant fuzzy set $A(x)=\frac{1}{2}$ for all $x \in X$.

3. $E(A) \geq E(B)$ if $A$ is 'more fuzzy' than $B$ by the 'sharpen' order.

4. $\mathrm{E}(\mathrm{A})=\mathrm{E}\left(\mathrm{A}^{\prime}\right)$.

Note that the defined entropy measure of a fuzzy set is a fuzzy $\prec$-measure where the $\prec$ preorder is the $\leq_{S}$ sharpen order, in which $\mathrm{B} \leq_{S} \mathrm{~A}$ if for any element $\mathrm{x}$ in the universe of discourse when $\mathrm{A}(\mathrm{x}) \leq \frac{1}{2}$ then $\mathrm{B}(\mathrm{x}) \leq \mathrm{A}(\mathrm{x})$ and when $\mathrm{A}(\mathrm{x}) \geq \frac{1}{2}$ then $\mathrm{B}(\mathrm{x}) \geq \mathrm{A}(\mathrm{x})$

Kaufmann [1975] proposes a fuzziness index as a normal distance. Other authors as Yager [1979] and Higashi and Klir [1983] understand the entropy measures as the difference between a fuzzy set and its complementary fuzzy set.

A new proposal for entropy measure given by a t-norm, a t-conorm and a negation is as follows:

Let $H: \wp \rightarrow[0,1], \mathbf{H}(\mu)=\mathbf{k ~ S}_{\mathbf{x} \in \mathbf{U}}\{\mathbf{T}(\mu(\mathbf{x}), \mathbf{N}(\mu(\mathbf{x}))\}$, where $\mu$ is a fuzzy set on $\mathrm{U}, \mathrm{k}$ is a constant that is used to normalise the measure and depends on the chosen continuous t-conorm $\mathrm{S}$, the continuous t-norm $\mathrm{T}$ and the strong negation $\mathrm{N}$.

It is easy to prove that if $\mu$ is crisp then $\mathrm{H}(\mu)=0$. If the t-norm $\mathrm{T}$ is the minimum or is in the family of the product t-norm, then $\mathrm{H}(\mu)=0$ if and only if $\mu$ is a crisp set. It is proved that $\mathrm{H}(\mu)=\mathrm{H}\left(\mu^{c}\right)$ by the symmetry property of the t-norms. When the t-norm $\mathrm{T}$ is the minimum or in the family of the product, then if $\mathrm{B} \leq_{\mathrm{S}} \mathrm{A}$ then $\mathrm{H}(\mathrm{B}) \leq \mathrm{H}(\mathrm{A})$. 
So the new proposed entropy verifies the properties given by De Luca and Termini [1972] when $\mathrm{T}$ is the minimum or in the family of the product $\mathrm{t}$ norm.

If the fuzzy set is on an infinite domain, the same result can be extended to the new expression

$$
\mathrm{H}(\mu)=\mathrm{k} \int_{x \in E}\{\mathrm{~T}(\mu(\mathrm{x}), \mathrm{N}(\mu(\mathrm{x}))\} . \mathrm{dx} .
$$

\subsection{Measures of Specificity}

The specificity measures introduced by Yager [1990] are useful as measures of tranquillity when making a decision. Yager introduces the specificity-correctness trade-off principle. The output information of expert systems and other knowledge-based systems should be both specific and correct to be useful. Yager suggests the use of specificity in default reasoning, in possibility-qualified statements and data mining processes, giving several possible manifestations of this measure. Kacprzyk [1990] describes its use in a system for inductive learning. Dubois and Prade [1999] introduce the minimal specificity principle and show the role of specificity in the theory of approximate reasoning. Higashi and Klir [1983] introduce a closely related idea called non-specificity. The concept of granularity introduced by Zadeh [1978] is correlated with the concept of specificity.

Let $X$ be a set with elements $\left\{x_{i}\right\}$ and let $[0,1]^{X}$ be the class of fuzzy sets of X. A measure of specificity $\mathrm{Sp}$ is a function $\mathrm{Sp}:[0,1]^{\mathrm{X}} \rightarrow[0,1]$ such that:

1. $\operatorname{Sp}(\mu)=1$ if and only if $\mu$ is a singleton $\left(\mu=\left\{x_{1}\right\}\right)$.

2. $\operatorname{Sp}(\varnothing)=0$

3. If $\mu$ and $\eta$ are normal fuzzy sets in $X$ and $\mu \subset \eta$, then $\operatorname{Sp}(\mu) \geq \operatorname{Sp}(\eta)$.

A general expression [L. Garmendia; R. R. Yager; E. Trillas y A. Salvador, 2003] that can be used to build measures of specificity from three t-norms and negations is an application $\operatorname{Sp}_{\mathrm{T}}:[0,1]^{\mathrm{X}} \rightarrow[0,1]$ defined by $\operatorname{Sp}_{\mathrm{T}}(\mu)=$ $\mathbf{T}_{1}\left(\mathbf{a}_{1}, \mathbf{N}\left(\mathbf{T}_{2}{ }^{*}{ }_{\mathrm{j}=2, \ldots, \ldots}\left\{\mathbf{T}_{3}\left(\mathbf{a}_{\mathbf{j}}, \mathbf{w}_{\mathbf{j}}\right)\right\}\right)\right.$ where $\mu$ is a fuzzy set in a finite set $\mathrm{X}$, and $a_{i}$ is the membership degree of the element $x_{i}\left(\mu\left(x_{i}\right)=a_{i}\right)$, the membership degrees $a_{i} \in[0,1]$ are totally ordered with $a_{1} \geq a_{2} \geq \ldots \geq a_{n}, N$ is a negation, let $\mathrm{T}_{1}$ and $\mathrm{T}_{3}$ be any t-norms, $\mathrm{T}_{2}{ }^{*}$ a $\mathrm{n}$-argument $\mathrm{t}$-conorm and $\left\{\mathrm{w}_{\mathrm{j}}\right\}$ is a weighting vector.

For example, when $\mathrm{N}$ is the negation $\mathrm{N}(\mathrm{x})=1-\mathrm{x}, \mathrm{T}_{1}$ and $\mathrm{T}_{2}$ are the $\mathrm{\iota u}-$ kasiewicz t-norm defined by $\mathrm{T}_{1}(\mathrm{a}, \mathrm{b})=\max \{0, \mathrm{a}+\mathrm{b}-1\}$, so $\mathrm{T}_{2} *\left(\mathrm{a}_{1}, \ldots, \mathrm{a}_{\mathrm{n}}\right)=$ $\min \left\{1, \mathrm{a}_{1}+. .+\mathrm{a}_{\mathrm{n}}\right\}$, and $\mathrm{T}_{3}$ is the product, then the previous expression gives Yager's [1990] linear measure of specificity, defined as 


$$
\operatorname{Sp}(\mu)=\mathrm{a}_{1}-\sum_{j=2}^{n} \mathrm{w}_{\mathrm{j}} \mathrm{a}_{\mathrm{j}}
$$

The measures of specificity are not monotone measures, because the measure of specificity of a fuzzy set is lower when some membership degrees that are not the highest degree are increased. However the measures of specificity of fuzzy sets are fuzzy $\prec$-measures, where $\prec$ is a preorder that classifies the fuzzy sets by the utility of the contained information, or by a given distance to a singleton.

Let $\mathrm{A}$ be a fuzzy set on an infinite universe $\mathrm{X}$ and let $\mathrm{A}_{\alpha}$ be its $\alpha$-cut.

R. R. Yager [1998] defines a measure of specificity on a continuous domain $\operatorname{Sp}$ as $\operatorname{Sp}(\mathrm{A})=\int_{0}^{\alpha_{\max }} \mathrm{F}\left(\mathrm{M}\left(\mathrm{A}_{\alpha}\right)\right) \mathrm{d} \alpha$, where $\alpha_{\max }$ is the maximum membership degree of $\mathrm{A}$ and $\mathrm{F}$ is a function $\mathrm{F}:[0,1] \rightarrow[0,1]$ verifying that $\mathrm{F}(0)=1, \mathrm{~F}(1)=0$, and $\mathrm{F}(\mathrm{x}) \leq \mathrm{F}(\mathrm{y}) \leq 0$ when $\mathrm{x}>\mathrm{y}$.

For example, the expression $\int_{0}^{\alpha_{\max }} \operatorname{Length}\left(\mathrm{A}_{\alpha \mathrm{i}}\right) \mathrm{d} \alpha$ can be interpreted as the area under the fuzzy set A. So, the measure of specificity under a fuzzy set under an interval $[\mathrm{a}, \mathrm{b}]$ can be interpreted as

$$
\alpha_{\max }-\frac{\text { area under A }}{\mathrm{b}-\mathrm{a}} \text {. }
$$

The measures of specificity of fuzzy sets on infinite universes can be given by an expression

$$
\operatorname{MS}(A)=\mathrm{T}_{1}\left(\alpha_{\max }, \mathrm{N}\left(\int_{0}^{\alpha_{\max }} \mathrm{T}_{2}\left(\mathrm{M}\left(\mathrm{A}_{\alpha}\right), \mathrm{d} \alpha\right)\right)\right)
$$

where $\int_{0}^{\alpha_{\max }}$ is a Choquet integral, $\mathrm{T}_{1}$ and $\mathrm{T}_{2}$ are t-norms and $\mathrm{N}$ is a negation.

Yager [1991] introduced the concept of specificity of a fuzzy set under similarities using the Zadeh [1971] concept of similarity or Minindistinguishability.

The $\alpha$-cut of a similarity $S$ is a classical equivalence relation denoted $S_{\alpha}$. Let $\pi_{\alpha}$ be the set of equivalence classes of S for a given value $\alpha$. Let $\mu_{\alpha} / S$ 
be the set of equivalence classes of $\pi_{\alpha}$ defined in the following way: class $\pi_{\alpha}(\mathrm{i})$ belongs to $\mu_{\alpha} / \mathrm{S}$ if there exists an element $\mathrm{x}$ contained in $\pi_{\alpha}(\mathrm{i})$ and in the $\mu^{\prime}$ s $\alpha$-cut $\left(\mu_{\alpha}\right)$.

Yager [1991] definition of measure of specificity of a fuzzy set $\mu$ under a similarity is the following:

$$
\mathrm{S}_{\mathrm{p}}(\mu / \mathrm{S})=\int_{0}^{\alpha_{\max }} \frac{1}{\operatorname{Card}\left(\mu_{\alpha} / S\right)} \mathrm{d} \alpha .
$$

\subsection{Measures of $\mu$-T-Unconditionality}

The $\mu$-T-conditionality property of fuzzy relations generalises the modus ponens property when making fuzzy inference. A fuzzy relation R: $E_{1} \times E_{2} \rightarrow[0,1]$ is $\mu$-T-conditional if and only if $T(\mu(a), R(a, b)) \leq \mu(b)$ for all $(\mathrm{a}, \mathrm{b})$ in $\mathrm{E}_{1} \times \mathrm{E}_{2}$.

Some ways to measure a degree of verification of this property are discussed, which are monotonous measures on the measurable space $(\mathfrak{R}, \mathfrak{I}$, $\mathrm{M})$, where $\mathfrak{R}$ is the set of fuzzy relations $\mathrm{R}: \mathrm{E}_{1} \times \mathrm{E}_{2} \rightarrow[0,1], \mathfrak{I}$ the set of measurable subsets of $\Re$ and $\mathrm{M}$ is a measure of $\mu$-T- unconditionality. There are two ways to define those measures [L. Garmendia; E. Trillas; A. Salvador; C. Moraga, 2005]. A first way computes a generalised distance between a fuzzy relation $\mathrm{R}$ and the greatest $\mu$-T-conditional relation that is contained in $\mathrm{R}$. The other way measures the difference between $\mathrm{T}(\mu(\mathrm{a})$, $\mathrm{R}(\mathrm{a}, \mathrm{b}))$ and $\mu(\mathrm{b})$ in all points $(\mathrm{a}, \mathrm{b})$ in which $\mathrm{R}$ is not $\mu$-T-conditional.

Let $\mathrm{J}^{\mathrm{T}}(\mathrm{x}, \mathrm{y})=\operatorname{Sup}\{\mathrm{z}: \mathrm{T}(\mathrm{x}, \mathrm{z}) \leq \mathrm{y}\}$ be the residual operator of a t-norm $\mathrm{T}$, let $\mathrm{J}_{\mu}^{\mathrm{T}}(\mathrm{a}, \mathrm{b})=\mathrm{J}^{\mathrm{T}}(\mu(\mathrm{a}), \mu(\mathrm{b}))$, and let $\mathrm{T}_{\mathrm{R}}^{\mu}(\mathrm{a}, \mathrm{b})=\mathrm{T}(\mu(\mathrm{a}), \mathrm{R}(\mathrm{a}, \mathrm{b}))$. In Garmendia [2003] it is proved that $\mathrm{J}^{\mathrm{T}}\left(\mathrm{R}(\mathrm{a}, \mathrm{b}), \mathrm{J}_{\mu}^{\mathrm{T}}(\mathrm{a}, \mathrm{b})\right)=\mathrm{J}^{\mathrm{T}}\left(\mathrm{T}_{\mathrm{R}}^{\mu}(\mathrm{a}, \mathrm{b}), \mu_{2}(\mathrm{a}, \mathrm{b})\right)$ for all continuous t-norms, which shows that when a generalised distance defined from a residuated operator of the T-norm is used, both methods set the same measures of $\mu$-T-unconditionality of fuzzy relations.

So, given any continuous t-norm $\mathrm{T}$, for all $(\mathrm{a}, \mathrm{b})$ in $\mathrm{E}_{1} \times \mathrm{E}_{2}$, the distance 1-J $\mathrm{J}^{\mathrm{T}}$ between a fuzzy relation $R$ in the point $(a, b)$ and its $\mu$-T-conditionalized relation $\mathrm{J}_{\mu}^{\mathrm{T}}(\mathrm{a}, \mathrm{b})$, is the same than the distance $1-\mathrm{J}^{\mathrm{T}}$ between $\mathrm{T}_{\mathrm{R}}^{\mu}(\mathrm{a}, \mathrm{b})$ and $\mu(b)$.

Some operators are frequently used to make fuzzy inference. The fuzzy operators are fuzzy relations on the universe $\mathrm{E}_{1} \times \mathrm{E}_{2}=[0,1] \times[0,1]$. 
The following examples show the evaluation of the measures for some implication operators. For all of them, the fuzzy set $\mu$ is taken as the identity (that is, as a function $\mu:[0,1] \rightarrow[0,1]$ such that $\mu(\mathrm{x})=\mathrm{x}$ ).

The chart bellow gives the measures of the most used residual implication operators, S-implications, QM-implications and conjunctions for the tnorms minimum, product and Łukasiewicz:

Table 1: measures of Id-T-unconditionality of some operators

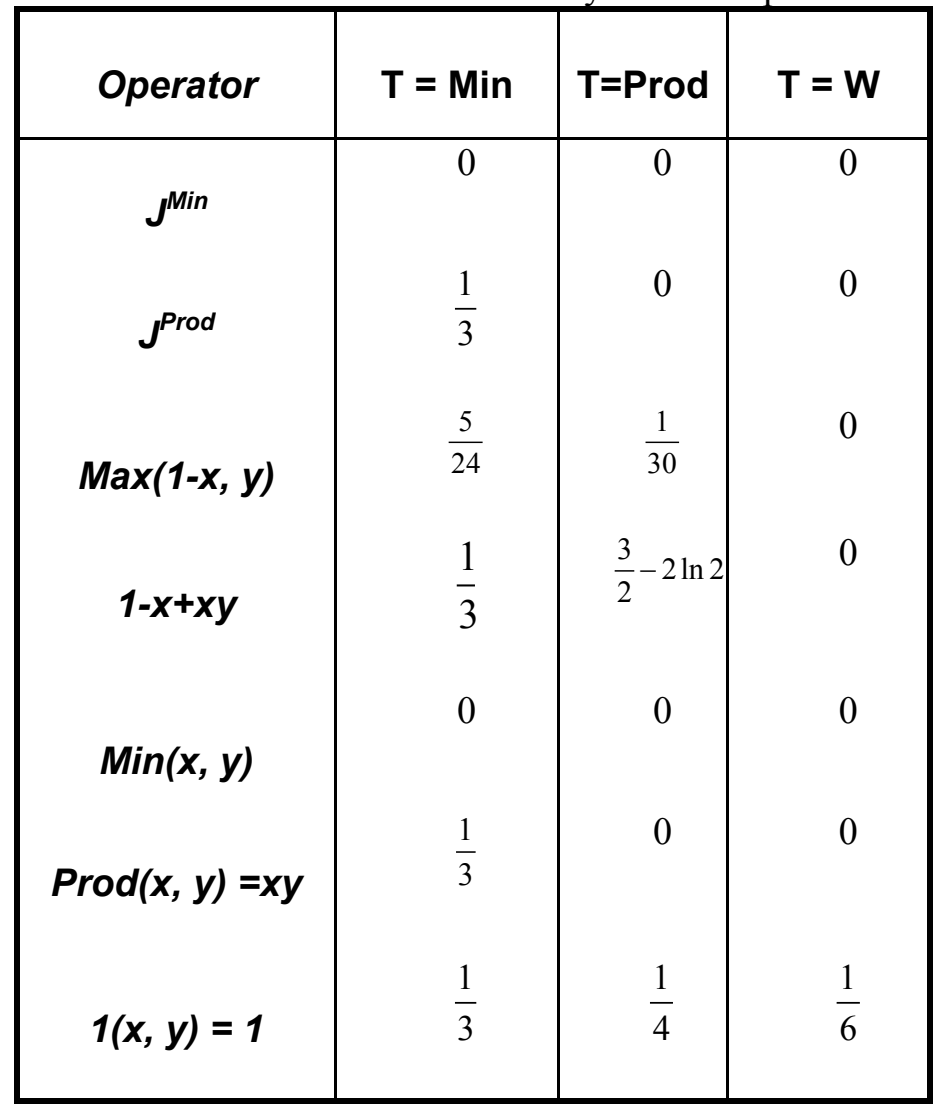

The measures of $\mu$-T- unconditionality of fuzzy relations are monotone measures on the measurable space $(\mathfrak{R}, \mathfrak{I}, M)$ where $\mathfrak{R}$ is the set of fuzzy relations $\mathrm{R}: \mathrm{E}_{1} \times \mathrm{E}_{2} \rightarrow[0,1]$, $\mathfrak{I}$ is the set of measurable subsets of $\mathfrak{R}$ and $\mathrm{M}$ is a measure of $\mu$-T- unconditionality. 


\section{Conclusions}

This paper presents an overview of the evolution of the concept of fuzzy measure. Some of these are relevant to understand the process of inference, even when these are neither additive nor monotone. Proposals for nonmonotone measures on fuzzy sets (entropy and specificity) are presented. They can be considered to be measures of information on the premises or conclusions in approximate reasoning. Finally some results are discussed on a monotone measure on fuzzy relations to understand whether or with which logics is the modus ponens generalised when making fuzzy inference.

\section{Acknowledgment}

This research is partially supported by the Spanish MCyT project BFM2002-00281.

\section{References}

Denneberg D (1994) Non-additive Measure and Integral, Kluwer Academic Publishers, Dordrecht,

Drewnowski L (1978) On the continuity of certain non-additive set functions. Colloquium Math. 38 pp. 243-253.

Dubois D, Prade H (1980) Fuzzy Sets and Systems. Theory and its Applications. Academic Press, New York,

Dubois D, Prade H (1982) A class of fuzzy measures based on triangular norm. A general framework for the combinations of uncertain information. Int. J. Gen. Syst. 8, 1, pp. 43-61.

Dubois D, Prade H (1987) The principle of minimum specificity as a basis for evidential reasoning. In: Uncertainty in Knowledge-based Systems, Bouchon, B. \& Yager RR (Eds.). Springer-Verlag, Berlin, pp. 75-84.

Dubois D, Prade H (1995) A note on measures of specificity for fuzzy sets. International Journal of General Systems 10, pp. 279-283.

Garmendia L, Campo C, Cubillo S, Salvador A (1999) A Method to Make Some Fuzzy Relations T-Transitive. International Journal of Intelligence Systems. 14 (9), pp. 873-882.

Garmendia L, Yager R, Trillas E, Salvador A (2003) On t-norms based specificity measures. Fuzzy Sets and Systems 133-2, pp. 237-248. 
Garmendia L Trillas E, Salvador A, Moraga C (2005) On measuring $\mu-T$ conditionality of fuzzy relations. Soft Computing. Springer-Verlag. Volume 9, Number 3, pp. $164-171$.

Grabisch M, Murofushi T, Sugeno M (1992) Fuzzy measure of fuzzy events defined by fuzzy integrals. Fuzzy Sets and Systems 50, pp. 293313.

Grabisch M, Murofushi T, Sugeno M (2000) Fuzzy Measures and Integrals Theory and Applications. Physica-Verlag.

Ha M, Wang X (1997) Some notes on the regularity of fuzzy measures on metric spaces. Fuzzy Sets and Systems 87, pp. 385-387.

Halmos PR (1968) Measure Theory, Van Nostrand, Princeton, NJ (1962). Van Nostrand Reinhold, New York.

Higashi M, Klir GJ (1983) Measures of uncertainty and information based on possibility distributions. International Journal of General Systems 9, pp. 3-58.

Jang LC, Kwon JS (2000) On the representation of Choquet integrals of set-valued functions, and null sets, Fuzzy Sets and Systems, 112, pp. 233239.

Jiang Q, Suzuki H (1996) Fuzzy measures on metric spaces. Fuzzy Sets and Systems 83, pp. 99-106.

Murofushi T, Sugeno M (1989) An interpretation of fuzzy measures and the Choquet integral as an integral with respect to a fuzzy measure. Fuzzy sets and Systems, pp 201-227.

Murofushi T, Sugeno M (1991) Fuzzy t-conorm integral with respect to fuzzy measures: generalization of Sugeno integral and Choquet integral, Fuzzy Sets and Systems 42, pp. 57-71.

Murofushi T, Sugeno M (1991) A theory of fuzzy measures: representations, the Choquet integral and null sets. J. Math. Anal. Appl. 159, pp. 532549 .

Murofushi T, Sugeno M, Machida M (1994) Non-monotonic fuzzy measures and the Choquet integral. Fuzzy Sets and Systems 64, pp. 73-86.

Pradera A; Trillas E, Cubillo S (2000) On modus ponens generating functions. Internat. J. Uncertain. Fuzziness Knowledge Based Systems 8, 1, pp. 7-19.

Puri ML, Ralescu D (1982) A possibility measure is not a fuzzy measure (short communication). Fuzzy Sets and Systems, pp. 311-313.

Riera T, Trillas E (1982) From measures of fuzziness to Booleanity control. Fuzzy information and decision processes, 3-16. North-Holland, Amsterdam-New York.

Schmeidler D (1986) Integral representation without additivity. Proc. Amer. Math. Soc. 97, pp. 253-261. 
Schweizer B, Sklar A (1960) Statistical metric spaces. Pacific J. Math. 10, pp. 313-334.

Schweizer B, Sklar A . (1983)Probabilistic Metric Spaces. North-Holland. New York.

Shafer GA (1976) A Mathematical Theory of Evidence. Princeton.

Sugeno M $(975 ; 4)$ Theory of Fuzzy Integrals and its applications. Ph. D. Dissertation. Tokyo Institute of Technology.

Trillas E, Riera T, (1978) Entropies in finite fuzzy sets. Inform. Sci. 15, 2, pp. 159-168.

Trillas E, Sanchis C (1979) On entropies of fuzzy sets deduced from metrics. Estadistica Española 82-83, pp. 17-25.

Trillas E, Cubillo S (1992) Condicionales Exactos. Actas II Conferencia Estylf., pp. 1-15.

Trillas E (1992) On exact conditionals. Stochastica 13, 1, pp. 137-143.

Trillas E (1992) On Exact and Inexact Conditionals. Prc. IV International Conference On Information Processing and Management of Uncertainty in Knowledge-Based Systems, pp. 649-655.

Trillas E (1992) On fuzzy conditionals generalising the material conditional. IPMU'92. Advanced methods in artificial intelligence, pp. 85-100.

Trillas E, Alsina C (1993) Logic: going farther from Tarski? Fuzzy Sets and Systems, 53, pp. 1-13.

Trillas E, Cubillo S (1994) On monotonic fuzzy conditionals. Journal of Applied Non-Classical Logics, 4, 2, pp. 201-214.

Trillas E, Cubillo S, Rodriguez A (1994) On the identity of fuzzy material conditionals. Mathware Soft Computing 1, 3, pp. 309-314.

Wang Z, Klir G (1992) Fuzzy Measure Theory, Plenum Press, New York.

Wang Z, Klir GJ (1996) Fuzzy measures defined by fuzzy integral and their absolute continuity. J. Math. Anal. Appl. 203, pp. 150-165.

Wu C, Wang S, Ma M (1993) Generalized fuzzy integrals: Part I. Fundamental concepts. Fuzzy Sets and Systems 57, pp. 219-226.

Wu C, Ha M (1994) On the regularity of the fuzzy measure on metric fuzzy measure spaces. Fuzzy Sets and Systems 66, pp. 373-379.

Xuechang L (1992) Entropy, distance measure and similarity measure of fuzzy sets and their relations. Fuzzy Sets and Systems 52, pp. 305-318.

Yager RR (1979) On the measure of fuzziness and negation, part I: membership in the unit interval. International Journal of General Systems 5, pp 221-229.

Yager RR (1982) Measuring tranquillity and anxiety in decision making: An application of fuzzy sets. International Journal of General Systems 8, pp. 139-146.

Yager RR (1983) Entropy and specificity in a mathematical theory of evidence. International Journal of General Systems 9, pp. 249-260. 
Yager RR (1984) Approximate reasoning as a basis for rule-based expert systems. IEEE Trans. Systems Man Cybernet. 14 4, pp. 636-643.

Yager RR (1985) Measures of specificity for possibility distributions. In Proceedings of the IEEE Workshop on Languages for Automation: Cognitive Aspects in Information Processing, Palma de Mallorca, Spain, pp. 209-214.

Yager RR (1985) Reasoning with uncertainty for expert systems. Proceedings of the Ninth International Joint Conference on Artificial intelligence. Los Angeles, pp. 1295-1297.

Yager RR (1986) Toward a general theory of reasoning with uncertainty part I: nonspecificity and fuzziness. International Journal of Intelligent Systems 1, pp. 45-67.

Yager RR (1986) The entailment principle for Dempstes-Shafer granules. International Journal of Intelligent Systems 1, pp. 247-262.

Yager RR, Ovchinnikov S, Tong R, Nguyen H (1987) Fuzzy sets and applications. Selected papers by L. A. Zadeh. John Wiley \& Sons, New York.

Yager RR (1988) On ordered weighted averaging aggregation operators in multicriteria decision making. IEEE Trans. Systems, Man, Cybernet. 18, pp. 183-190.

Yager RR (1990) Ordinal measures of specificity. International Journal of General Systems 17, pp. 57-72.

Yager RR (1991) Measures of specificity of possibility distributions. Proceedings of the Tenth NAFIPS meeting, U. Of Missouri, Columbia, MO, pp. 240-241.

Yager RR( 1991) Similarity based measures of specificity. International Journal of General Systems 19, pp. 91-106.

Yager RR (1992) Default knowledge and measures of specificity. Information Sciences 61, pp. 1-44.

Yager RR (1992) On the specificity of a possibility distribution. Fuzzy Sets and Systems 50, pp. 279-292.

Yager RR (1998) On measures of specificity, Computational Intelligence: Soft Computing and Fuzzy-Neuro Integration with Applications, edited by Kaynak, O., Zadeh L. A., Turksen, B., and Rudas, I. J., Springer-Verlag, Berlin, pp. 94-113.

Yao J, Chang S (2000) Fuzzy measure based on decomposition theory, Fuzzy Sets and Systems, 112, pp. 187-205.

Zadeh LA (1965) Fuzzy sets. Information and Control 8, pp. 338-353.

Zadeh LA (1971) Similarity relations and fuzzy orderings, Inform. Sci. 3, pp. 177-200. 